\title{
VERBAL BEHAVIOR ANALYSIS AS A SUPERVISORY TECHNIQUE WITH STUDENT TEACHERS OF MUSIC
}

\section{Ralph E. Verrastro}

The purpose of the study was to determine the differential influence of a supervisory process based on constructs derived from the Withall Social-Emotional Climate Index on verbal behavior patterns exhibited by student teachers of music, their ability to engage in objective self-assessment, and the effect of such activity on the students' percepts of teacher-role ideology. The results indicated that: (1) student teachers of music appear not to be predisposed to the employment of learner-centered instructional behavior; (2) student teachers of music can be sensitized to the employment of both learner-centered and teacher-centered verbal patterns in accordance with the purpose and nature of the instruction being provided; and (3) verbal behavior analysis supervision tends to encourage objective self-assessment and provides a functional and commonly defined basis for the systematic improvement of teaching performance.

Key Words: behavior modification, psychological processes, teaching ability, teacher training.

Music teachers, both student and veteran, have a predeliction to view the music teaching task from a somewhat personal point of view, equating success in terms of their own performance and ability to direct musical activities. Student teachers, however, are still at a somewhat maleable stage with regard to teaching attitudes, strategies, and behaviors. It would seem logical that since these professional behavior patterns are not yet irrevocably established, student teachers can be guided in the development of behaviors and consequent attitudes that are in consonance with the purposes of music education in the public schools.

Student teacher supervision provides the prospective teacher with a guided preservice internship. Essential to this task are supervisory 
value-judgments regarding the performance and effectiveness of the student teacher. Through conference interactions, the supervisor provides reinforcement for those behaviors so deserving and offers guidance where observation has disclosed a deficiency. Of parallel importance, supervision should initiate a process of self-evaluation to the extent that continuous inservice education can evolve. According to some observers, the element lacking in this process is a commonly defined theory of what constitutes good or appropriate teaching behavior. Surplus, for example, has concluded that "at the present time, teachers must infer how they should behave from what they know about learners and the learning process." Gage assailed this weakness in teacher education when he proposed that "theories of teaching would make explicit how teachers behave, why they behave as they do, and with what effects."' Concerning the phenomenon of teacher behavior, Medley and Mitzel state:

The important differences between teachers are most likely to be found in broader patterns of behavior manifested now in one specific behavior, now in another. . . It is a fortunate fact, and one that might not have been foreseen, that a relatively small number of signs will suffice in many cases to measure a broader behavior pattern with satisfactory reliability. ${ }^{3}$

\section{Rationale}

Recent research by Aschner, Flanders, and Withall generalize that of the many and complex types of teacher behavior, verbal behavior and resultant teacher-learner interactions can be among the most crucial.4 Withall, a pioneer in teacher behavior analysis, has defined the affective tone that results from teacher verbal behavior as a social-emotional learning climate, a phenomenon that can be adequately measured and quantified by teacher verbal behavior alone.

Teacher verbal statements and patterns, as categorized on the Withall Social-Emotional Climate Index, can be classified and described as a ratio between learner-oriented and teacher self-oriented instructional influence.

\footnotetext{
${ }^{1}$ Robert A. Surplus, "Toward a Theory of Student Teaching in Music" (paper read at the MENC Southern Division Biennial Meeting, April 28, 1967, Atlanta, Gcorgia).

"N. L. Gage, "Paradigms for Research on Teaching," Handbook of Research on Teaching, ed. N. L. Gage (Chicago: Rand McNally and Co., 1963), p. 309.

${ }^{3}$ Donald M. Medley and Harold E. Mitzel, "Measuring Classroom Behavior by Systematic Observation," Handbook of Research on Teaching, ed. N. L. Gage (Chicago: Rand McNally and Co., 1963), p. 309.

"Mary Jane McCue Aschner, "The Analysis of Verbal Interaction in the Classroom," Theory and Research in Teaching, ed. Arno A. Bellack (New York: Columbia University, Bureau of Publications, 1963), pp. 53-78; Ned Flanders, "Teacher Influence, Pupil Attitude and Achievement: Studies in Interaction Analysis," U. S. Office of Education Cooperative Research Project, No. 397 (Minneapolis: University of Minnesota, 1960); John Withall, "The Development of a Technique for the Measurement of SocialEmotional Climate in Classrooms," Interaction Analysis: Theory, Research, and Application, eds. E. Amidon and J. Hough (Reading, Massachusetts: Addison-Wesley Publishing Co., 1967).
} 
The resultant ratio describes the classroom climate as being either learner-centered or teacher-centered. A learner-oriented climate is one in which the predominance of verbal behavior is supportive, acceptant, and problem-structuring. A self-oriented climate is one in which the major portion of teacher statements are directive, reproving, or teacher selfsupportive. Withall concluded that a classroom atmosphere conducive to learning is synonymous with a compatible ratio between learner-centered and teacher self-centered instructional influence.

Based on the Climate Index, Flanders developed a classification procedure that can be used to categorize and quantify both the teacher's and learner's verbal behavior. ${ }^{5}$ Flanders' frame of reference, termed "Categories for Interaction Analysis," differentiates teacher behavioral influence as being either direct or indirect. Empirically concerned with both the process and product of the teaching act, Flanders' investigation confirmed that teaching behaviors described as indirect (learner-centered) produce more student achievement and positive attitude development, and that teachers naturally predisposed to this style of teaching show more adeptness and flexibility in adapting their influence to the requirements of the learning situation or nature of the instructional setting.

Additional studies concerned with classroom interaction by Medley and Mitzel, Shapiro, and Hough also have attempted to assess the several behaviors of teachers and the effect of various influences on the learning process. ${ }^{6}$ However, significant development beyond the pioneering efforts of Withall and Flanders is difficult to determine. Flanders comments on the potential and limitations of the present modicum of knowledge relative to teacher behavior and resultant classroom climate: "Even though the research on climate ... is restricted to generalized, broad patterns of teacher behavior, it does make a fundamental contribution to a theory of instruction. This contribution consists of identifying general patterns of the teachers influence that produce predictable responses."7

\section{Purpose}

The purpose of the study was to determine the differential influence of a supervisory process based on constructs derived from the Social-Emotional Climate Index on verbal behavior patterns exhibited by student teachers of music, their ability to engage in objective self-assessment, and

${ }^{5}$ Flanders, Appendix F, p. 5.

${ }^{6}$ Donald M. Medley and Harold E. Mitzel, "A Technique for Measuring Classroom Behavior," Journal of Educational Psychology, Vol. 49 (April 1958); Edna Shapiro, "Study of Children Through Observation of Classroom Behavior," Theory and Research in Teaching, ed. Arno A. Bellack (New York: Columbia University, Bureau of Publications, 1963), pp. 91-101; John B. Hough, "An Observational System for the Analysis of Classroom Interaction" (unpublished paper, Ohio State University, 1964).

${ }^{7}$ Ned Flanders, "Teacher Influence in the Classroom," Interaction Analysis: Theory', Research and Application, eds. E. Amidon and J. Hough (Reading, Massachusetts: Addison-Wesley Co., 1967), p. 108. 
the effect of such activity on the students' percepts of teacher-role ideology. ${ }^{8}$

\section{Procedures}

The experiment was conducted in conjunction with the off-campus student-teaching program at the School of Music, East Carolina University, Greenville, North Carolina. The student-teacher subjects involved in the study $(n=39)$ were randomly selected from an extant group of senior music education majors and then randomly assigned to either the control or experimental group. Eight student teachers were assigned to the experiment during each of five consecutive twelve-week terms. Placement of subjects was restricted to the cooperating schools normally used in the student-teaching program. Supervision of the student teachers was the joint responsibility of the college supervisors as assigned by the dean of the music school, and the supervising teachers who were professionally employed by the cooperating school districts.

The Rokeach Scale and Eidell Ideology Measure were administered to all subjects prior to their reporting to the off-campus student teaching center to which they were assigned. The Ideology Measure was readministered during the final week of the student-teaching term. The Rokeach Scale was used to study verbal behavior data relative to the personality trait of open- and closed-mindedness. The Ideology Measure served as a pre-post measurement of maturation-treatments changes in teacher-role ideology, and as a source of potential covariate data in the analysis of verbal behavior ratios. The experimental design employed in this aspect of the study follows the nonequivalent group pretest-posttest experiment described by Campbell and Stanley. ${ }^{9}$

A mid-and final-term self-evaluation was required of each student teacher involved in the study. An adaptation of the Summary Evaluation Form was used for this purpose.10 These data were routinely secured during the campus seminar periods. For purposes of comparative analysis, supervising teachers were requested to complete a similar form.

Using the Whitall procedure for verbal statement classification, each student teacher's verbal behavior was recorded on five occasions during each term. Information relating to the grade level, nature of the instructional setting, and chronological number of the observation was noted. Observations for gathering verbal behavior samples were systematically scheduled over the course of each twelve-week term. The experimental procedure employed in the evaluative and classroom observation phase of the study approximates the time-series experiment suggested by

\footnotetext{
${ }^{8} \mathrm{John}$ Withall, pp. 47-64.

"Donald T. Camphell and Julian C. Stanley, Experimental and Quasi-Experimental Designs for Research (Chicago: Rand McNally and Co., 1967), pp. 47-50.

${ }^{10}$ David H. Mathis, The Terminal Evaluation of Student Teachers (doctoral dissertation, Colorado State College, 1965).
} 
Campbell and Stanley. ${ }^{11}$ It should be noted that the evaluative aspects of the study were exclusive of the procedures employed for recording progress and deriving academic grades and were conducted anonymously.

The two treatments employed in the study were administered during conference sessions with the student-teacher subjects and differed in emphasis rather than nature. In the control group, the follow-up conference was characterized by the analysis and evaluation of the purpose, development, and learning outcomes of the lesson observed. In the experimental group, emphasis was directed toward a cause and effect analysis of the verbal behavior exhibited by the student teacher during the observed lesson. In each case, the conferences were nondirective and endeavored to foster objective self-assessment.

\section{Findings}

The preliminary analysis of the data revealed that correlations between the scores on the Rokeach Scale and a pretreatment sampling of student teacher verbal behavior, and ratings on the Ideology Measure and the same data, were not significant. Thus, these data were not considered as covariates in the analysis of verbal behavior ratios. The preliminary analysis of the data further disclosed the internal consistence reliability of the adapted versions of the Summary Evaluation Form to be .924 for the student teachers, and .932 for the supervising teachers. ${ }^{12}$

The first null hypothesis of the study, which stated that the mean verbal behavior ratios for the two treatment groups would be equal, was tested by a two-factor analysis of variance. The analysis resulted in the

Table 1

Analysis of Variance of Verbal Behavior Ratios

\begin{tabular}{lcrcc}
\hline Source of Variation & Sum of Squares & d. f. & Mean Squares & F-Ratio \\
\hline Between Subjects & 2.6767 & 38 & & \\
$\quad$ Treatments & 1.3505 & 1 & 1.3505 & $37.68^{*}$ \\
$\quad$ Error (b) & 1.3262 & 37 & .03584 & \\
Within Subjects & 2.0178 & 78 & & \\
$\quad$ Trials & .08556 & 2 & .04278 & 2.53 \\
Trials by Treatments & .68208 & 2 & .34104 & $20.19^{*}$ \\
$\quad$ Error (w) & 1.25016 & 74 & .01689 & \\
Total & 4.69450 & 116 & & \\
\hline
\end{tabular}

${ }^{*}$ Significant at the .001 level

${ }^{11}$ Campbell and Stanley, pp. 37-43.

${ }^{12}$ Equivalent to Kuder-Richardson Formula 20. 


\section{6/JRME}

rejection of the null hypothesis, as the student teachers experiencing the experimental treatment obtained significantly higher mean verbal behavior ratios than their counterparts in the control group. The analysis of the trials effect found that the verbal behavior patterns of the student teachers did not vary significantly over the number of conference sessions experienced.

The analysis of the trials by treatments interaction revealed that the verbal behavior patterns of the student teachers in the experimental group exhibited demonstrable gains in favor of the learner-centered categories, while the verbal patterns of subjects in the control group rose only slightly over the twelve-week term. The statistical summary pertinent to the first hypothesis and related subquestions is shown in Table 1. Mean verbal behavior ratios and standard deviations for each group and sampling occasion are shown in Table 2. A graphic represen-

Table 2

Mean Verbal Behavior Ratios and Standard Deviations

\begin{tabular}{clcc}
\hline $\begin{array}{c}\text { Observation } \\
\text { Occasion }\end{array}$ & Treatment Group & Mean* & Standard Deviation \\
\hline 1 & Control & .28 & .10 \\
3 & Control & .32 & .15 \\
5 & Control & .33 & .14 \\
1 & Experimental & .37 & .13 \\
3 & Experimental & .57 & .19 \\
5 & Experimental & .62 & .15 \\
\hline
\end{tabular}

* Mean Verbal Behavior Ratio indexes can be studied for deviation from the midratio value of . 50, indicating an equal balance between learner-centered and teacher-centered verbal behavior. Index values greater than .50 indicate a predominance of learnercentered verbal behavior; coversely, values less than .50 indicate a predominance of teacher-centered verbal behavior.

tation of the obtained interaction is provided in Figure 1. In addition, a visual examination of the verbal behavior data provided little evidence of major variation in the verbal patterns of the student teachers by grade level or instructional setting. For reference, these data are shown in Table 3 .

The second null hypothesis of the study, which stated that means self and supervising teacher evaluation scores for the two treatment groups would be equal, was tested by a three-factor analysis of variance. ${ }^{13}$ As

${ }^{13}$ A computer program (AOVRM) written by Nancy C. Daubert based on the three-factor experiment described by B. J. Winer, Statistical Principles in Experimental Design (New York: McGraw-Hill Co., 1962), pp. 323-335. The program is designed to handle factorial analysis of variance with repeated measures and equal or unequal sample sizes. 
Figure 1.

The Interaction of Mean Verbal Behavior Ratios for Observations One, Three, and Five

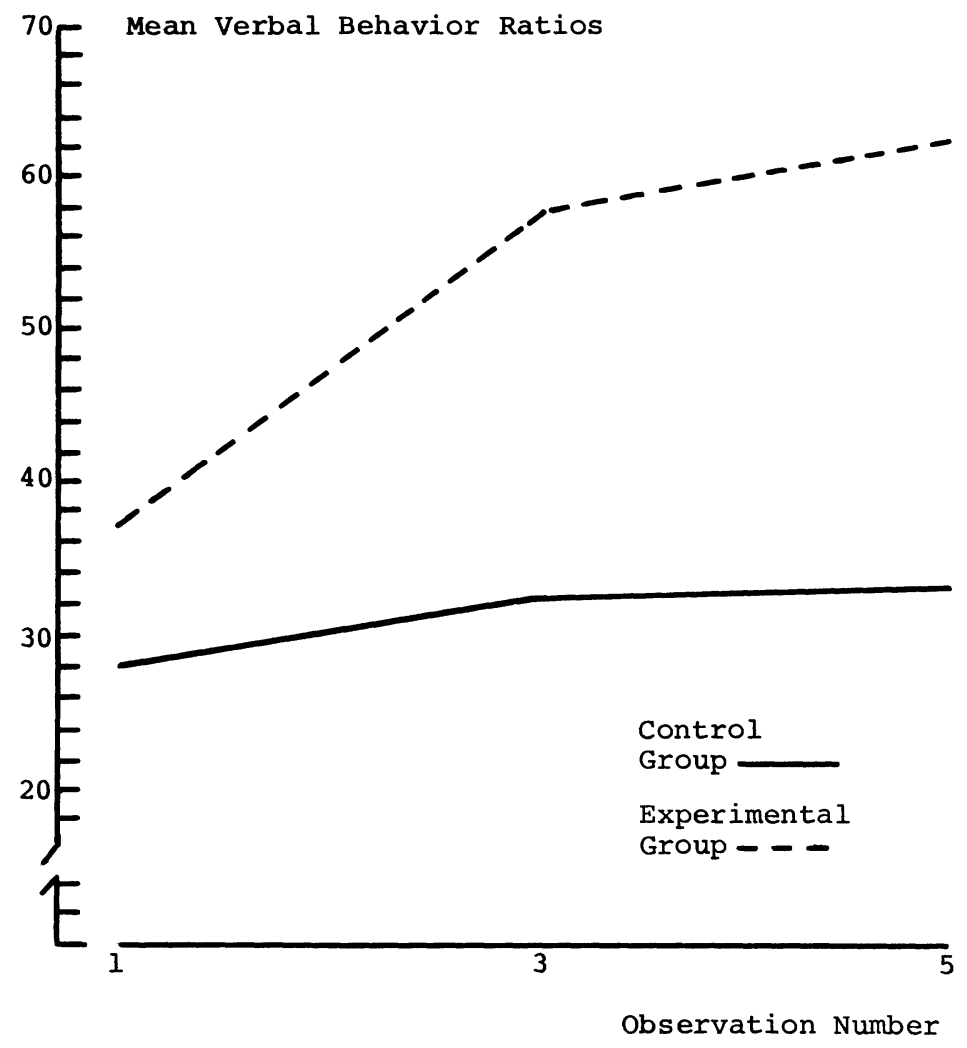

Table 3

Mean Verbal Behavior Ratios and Standard Deviations by Grade Level and Instructional Setting

\begin{tabular}{|c|c|c|c|c|c|c|}
\hline \multirow[b]{2}{*}{ Instructional Setting } & \multicolumn{2}{|c|}{$\begin{array}{l}\text { Elementary } \\
\text { Level Mean }\end{array}$} & \multicolumn{2}{|c|}{$\begin{array}{l}\text { Intermediate } \\
\text { Level Mean }\end{array}$} & \multicolumn{2}{|c|}{$\begin{array}{c}\text { Senior } \\
\text { Level Mean }\end{array}$} \\
\hline & $T_{1}$ & $\mathrm{~T}_{2}$ & $T_{1}$ & $\mathrm{~T}_{2}$ & $T_{1}$ & $T_{2}$ \\
\hline Instrumental Instruction & .31 & .57 & .31 & .51 & .25 & .47 \\
\hline Standard Deviation & .14 & .22 & .09 & .19 & .10 & .19 \\
\hline Choral-Vocal Instruction & & & .33 & .54 & .30 & .46 \\
\hline Standard Deviation & & & .06 & .12 & .10 & .16 \\
\hline General Music Instruction & .34 & .58 & .27 & .62 & & \\
\hline Standard Deviation & .06 & .18 & .11 & .17 & & \\
\hline
\end{tabular}

$T_{1}=$ Control group. $\quad T_{2}=$ Experimental group. 


\section{8/JRME}

shown in Table 4, the analysis of the main effects indicated that overall differences in evaluation ratings by treatment groups and self and supervising teacher evaluations could not be differentiated from chance. The analysis did find, however, that mean differences between mid- and finalterm evaluations were significant.

\section{Table 4}

Analysis of Variance of Self and Supervising Teacher Evaluations

\begin{tabular}{|c|c|c|c|c|}
\hline Source of Variation & $\begin{array}{l}\text { Sum of } \\
\text { Squares }\end{array}$ & d. $f$. & Mean Squares & F-Ratio \\
\hline \multicolumn{5}{|l|}{ Between Subjects } \\
\hline Treatments & .44273 & 1 & .44273 & .659 \\
\hline Error (b) & .24856 & 37 & .67179 & \\
\hline \multicolumn{5}{|l|}{ Within Subjects } \\
\hline Evaluators & .66051 & 1 & .66051 & 3.801 \\
\hline Treatments by Evaluators & .21635 & 1 & .21635 & $12.450^{*}$ \\
\hline Error (w) & .64296 & 37 & .17377 & \\
\hline Occasions & .37318 & 1 & .37318 & $16.589^{*}$ \\
\hline Treatments by Occasions & .99176 & 1 & .99176 & $44.088^{*}$ \\
\hline Error $(w)$ & .83232 & 37 & .22495 & \\
\hline Evaluators by Occasions & .18006 & 1 & .18006 & .074 \\
\hline $\begin{array}{l}\text { Treatments by Evaluators by } \\
\text { Occasions }\end{array}$ & .12508 & 1 & .12508 & .513 \\
\hline Error (w) & .90176 & 37 & .24372 & \\
\hline Total & .19723 & & & \\
\hline
\end{tabular}

*Significant at the .001 level

Further analysis indicated a significant interaction between treatments and self and supervising teacher evaluations. Student teachers in the control group evidenced higher mean self-evaluation scores than those provided by their supervising teachers; student teachers in the experimental group tended to rate themselves somewhat lower than their supervising teachers. The self and supervising teacher mean evaluation ratings for each treatment group are listed in Table 5.

\section{Table 5}

Mean Self and Supervising Teacher Evaluation Ratings for the Experimental and Control Groups

\begin{tabular}{lcc}
\hline \multicolumn{1}{c}{ Treatment Group } & Self Evaluation & $\begin{array}{c}\text { Supervising } \\
\text { Teacher Evaluation }\end{array}$ \\
\hline Control & 129.9 & 126.4 \\
Experimental & 119.1 & 130.5 \\
\hline
\end{tabular}


Figure 2.

The Interaction of Mean Self and Supervising Teacher Evaluation Ratings for Occasion One and Two

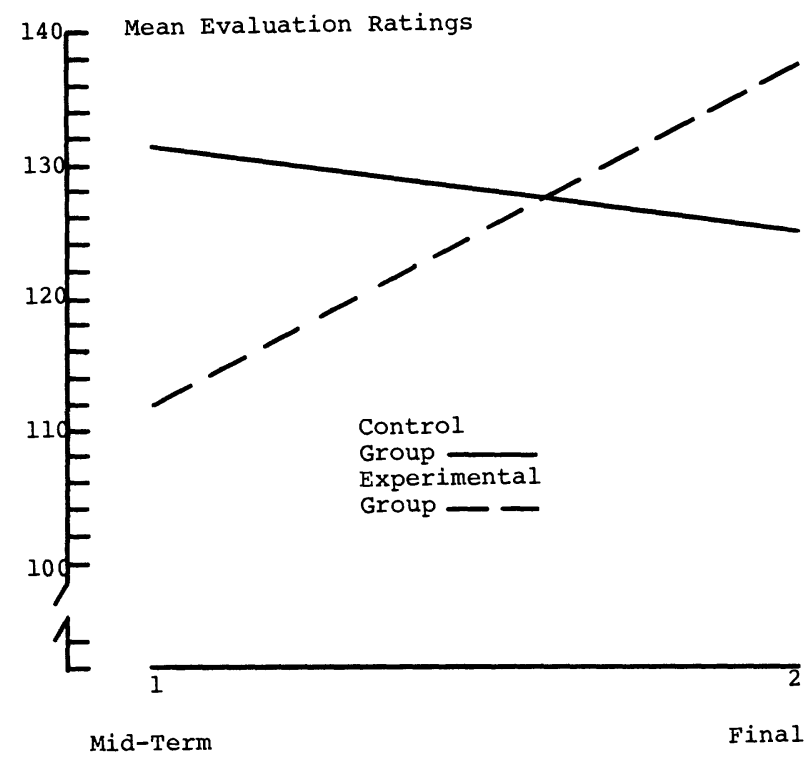

Administration Occasion one and Two

The interaction of treatments over mid- and final-term evaluation occasions was also significant. The combined self and supervising teacher mean evaluation ratings for the control group declined from the mid- to the final-term evaluation. Conversely, mean ratings for the experimental group evidenced considerable gain over the two evaluation occasions. The numerical equivalents in mean score values for each of the two treatment groups and evaluation occasions are listed in Table 6. The interaction is graphically represented in Figure 2.

\section{Table 6}

Combined Self and Supervising Teacher Mean Evaluation Ratings for Occasion One and Two

\begin{tabular}{lcc}
\hline Treatment Group & Occasion One & Occasion Two \\
\hline Control & 131.4 & 124.8 \\
Experimental & 112.1 & 137.4 \\
\hline
\end{tabular}


Table 7

Mean Evaluation Ratings by Treatments, Evaluators, and Administration Occasion

\begin{tabular}{lccc}
\hline Treatment Group & Evaluators & Occasion One & Occasion Two \\
\hline Control & Self & 132.6 & 127.2 \\
Experimental & Self & 107.6 & 130.5 \\
Control & Supervising Teacher & 130.2 & 122.5 \\
Experimental & Supervising Teacher & 116.6 & 144.3 \\
\hline
\end{tabular}

The interaction of self and supervising teacher ratings over mid- and final-term evaluation occasions, and the multiple interaction of treatments, occasions, and evaluators could not be differentiated from chance. A summary of mean evaluation ratings by treatments, evaluators, and occasions is provided in Table 7.

The third null hypothesis of the study, which stated that pretest-posttest mean ideology ratings for the two treatment groups would be equal, was tested by a two factor analysis of variance. As shown in Table 8, the obtained F-ratio was less than one. The null hypothesis was thus retained. The interaction of treatments over pretest-posttest trials was significant, however, as mean values for student teachers in the control group exhibited a slight rise in favor of the custodial pole of the Ideology Measure. In contrast, pretest-posttest mean values for the experimental group dropped slightly in favor of the humanistic pole. The interaction is illustrated in Figure 3.

\section{Conclusions}

As hypothesized, student teachers of music are not predisposed to employing indirect instructional behaviors as determined by the verbal

Table 8

Analysis of Variance of Pretest-Posttest Ideology Ratings

\begin{tabular}{lcccc}
\hline Source of Variation & Sum of Squares & d. f. & Mean Squares & F.Ratio \\
\hline Between Subjects & 4034.18 & 38 & & \\
Treatments & 4.935 & 1 & 4.935 & .0543 \\
Error (b) & 4029.245 & 37 & 108.899 & \\
Within Subjects & 940.50 & 39 & & \\
$\quad$ Trials & 19.50 & 1 & 19.50 & .897 \\
Trials by Treatments & 117.319 & 1 & 117.319 & $5.401^{*}$ \\
Error (w) & 803.681 & 37 & 21.721 & \\
Total & 4974.680 & 77 & &
\end{tabular}

*Significant at the .05 level 
Figure 3.

Treatments-Ideology Interaction Effect

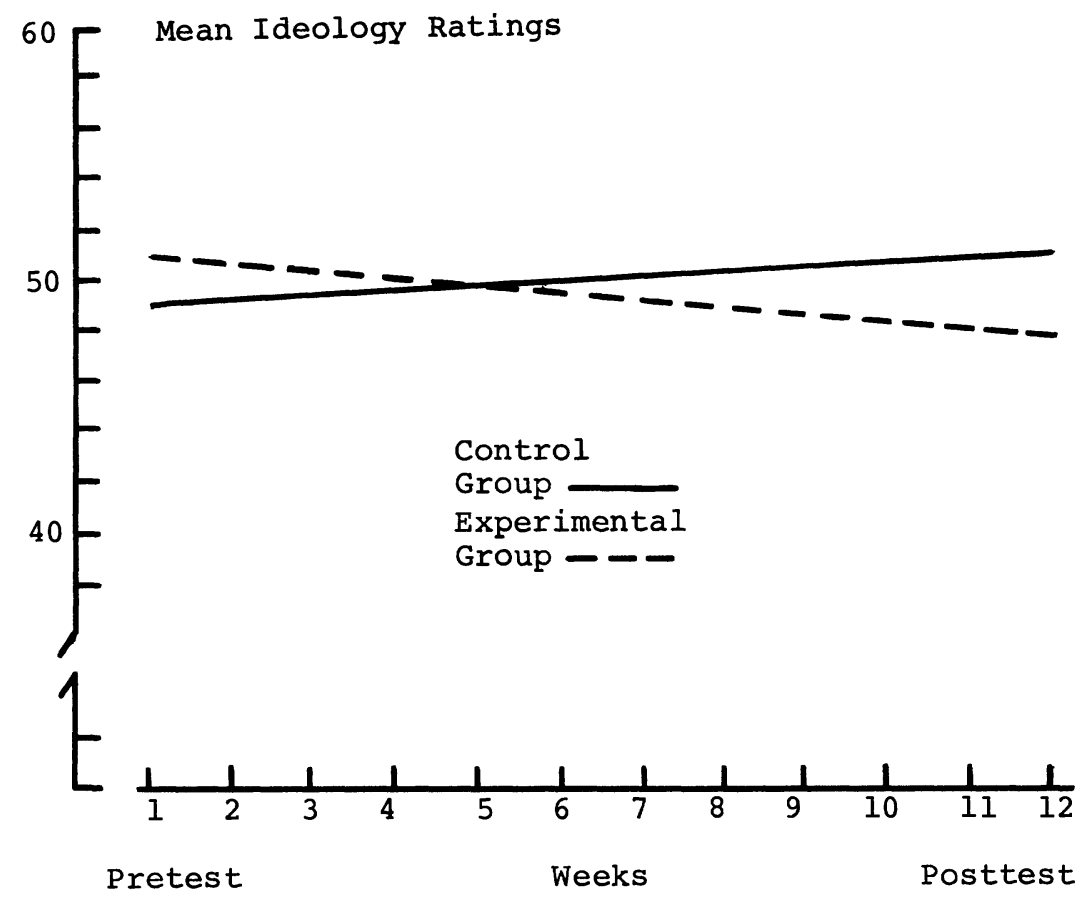

behavior sampling procedures used in the study. While this condition must derive from a variety of factors, including the tendency of teachers to engage in teaching behaviors based on recall of their experience as students, it has been suggested that the particular adjustment problems experienced by student teachers of music may also result from a lack of agreement on musical values, preferences, and aspirations between themselves and their pupils, and the difficulty encountered in establishing a positive and productive relationship with the classes to which they are assigned. ${ }^{14}$ As contributing factors, observations made by the investigator during the course of the study tend to support these viewpoints. In the absence of mutual purpose and a viable classroom rapport, student teachers of music seem inclined to engage in instructional pursuits and patterns of behavior that are more closely allied to their own special training and interest than they are reflective or considerate of the needs, interests, or achievement levels of their pupils.

Also consistent with the findings of previous research, the study indicates that student teachers of music can be caused to employ both

\footnotetext{
${ }^{14}$ Michael Esselstrom, The Role of the Supervisor of Student Teaching in Music (doctoral dissertation, Columbia University, 1968), pp. 122-124.
} 


\section{2/JRME}

learner-centered and teacher-centered verbal patterns in accordance with the purpose and nature of the instruction being provided. ${ }^{15}$ Whereas the investigators cited relied on training and feedback procedures, the results of the present study demonstrate that constructs derived from the research on classroom climate can be proffered in a nondirective manner, allowing the student teacher to come to his own terms with the principles involved. In view of the rather personal nature of the teaching act and the respective positions of the college supervisor and student teacher, this would seem an important factor if student-teacher behavioral changes are to possess the integrity necessary for carryover to inservice roles and activities.

In addition to the desirability of teachers appropriately employing learner-centered verbal patterns, the behaviors developed by the studentteacher subjects experiencing verbal behavior analysis supervision seem to conform to the behavioral criteria suggested by Evans for the rating and assessment of student-teacher performance:

Is the student teacher skilled in devising questions which stimulate and clarify the thinking of pupils? Does he rely heavily upon questioning, rarely giving answers, but instead helping the class find the answers? Does he make certain that each question asked by a pupil is heard and understood by all the group? Does he avoid loading questions, questions that can be answered by "yes" or "no?"16

As indicated by the verbal behavior ratios recorded and analyzed, it would appear that the verbal patterns of student teachers in music are rather stable and consistent. Aside from the differences obtained between each of the treatment groups, the recorded ratios evidenced little variation among the various curricular areas and grade levels in which the student-teacher subjects were observed.

Relatedly, the study did not find a significant relationship between the verbal patterns exhibited by the student-teacher subjects and the number of conference sessions experienced. The gains recorded for the student teachers in the experimental group were found to occur during the first six to eight weeks of the internship, after which a plateau apparently was reached. This finding suggests that sensitizing student teachers to an awareness of their verbal actions can be achieved in relatively few con-

\footnotetext{
${ }^{16}$ Richard Eves Ishler, An Experimental Study Using Withall's Index to Determine the Effectiveness of Feedback as a Means of Changing Student Teachers' Verbal Behavior (doctoral dissertation, The Pennsylvania State University, 1965), pp. 75-80; Richard D. Zahn, "The Use of Interaction Analysis in Supervising Student Teachers," Interaction Analysis: Theory, Research, and Application, eds. E. Amidon and J. Hough (Reading, Massachusetts: Addison-Wesley Co., 1967), pp. 295-298.

${ }^{10}$ John J. Evans, Case Reports of Institutional Practices, Chapter V, Evaluating Student Teaching: A Forward Look at Theories and Practices, Thirty-ninth yearbook of the Association for Student Teaching (Dubuque, Iowa: William C. Brown Co., 1960), p. 161 .
} 


\section{Verrastro/183}

ference sessions, and that the number of conferences experienced is not proportionately related to the verbal behavior exhibited in the classroom.

Since objective self-assessment was a goal for student teachers in each of the treatment groups, the occurrence and nature of the interactions generated give indication that such assessment was taking place. This conclusion is further supported when the rating reliability obtained by each group of evaluators is noted, and consideration is given to the anonymity surrounding the evaluative phase of the study.

Assuming objective levels of student-teacher self-assessment, the differences obtained between mid- and final-term evaluation occasions suggest that at mid-term, student teachers in the control group seemed stable and comfortable to both themselves and their supervising teachers. In contrast, student teachers in the experimental group at mid-term appeared somewhat unsettled and uncomfortable. This condition is understandable, for the earlier attempts to employ facilitating behaviors were observably awkward and not well understood by either pupils or supervising teachers. As skill and confidence in handling these techniques were gained, the reactions seemed to modify to the extent that final-term evaluations were far more positive and were considerably higher than the composite final evaluations recorded for the student teachers in the control group. The findings of the study also disclosed that while student teachers in the experimental group were inclined to evaluate their teaching performance somewhat below the ratings provided by their supervising teachers, the opposite condition prevailed with student teachers experiencing the control treatment.

In view of the evidence, it can be concluded that verbal behavior analysis as a technique of the college phase of supervision is corollary to levels of student teacher self-assessment that are more critical than opinions held by supervising teachers, and that it contributes to steady and impressive gains in composite evaluation estimates over the duration of the internship. While the specific occurrences described in the conclusions relating to student-teacher evaluation were unforeseen, they satisfy the intent of the second general hypothesis of the study and attest further to the potential value of verbal behavior analysis as a basis for the college phase of supervision with student teachers of music.

The teacher-role ideology of student teachers, as defined and determined in the study, do not seem to be demonstrably affected by the treatments employed in the investigation. It can be noted further that the ideology percepts held by most of the participants in the study were somewhat ambivalent, neither excessively custodial or humanistic.

The incident of a significant interaction between treatments and pretest-posttest trials on the Ideology Measure would seem to indicate that verbal behavior analysis tends to enhance the development of humanistic teacher-role percepts, while more traditional methods of supervision foster custodialism. This suggestion is somewhat inconclusive, however, as a visual examination of the data reveals that actual changes 


\section{4/JRME}

in ideology ratings over pretest-posttest trials were more pronounced for those subjects whose pretest scores varied more extremely from the midrange norms established by the combined groups. In most of these cases, pretest-posttest changes favored the direction indicated by the interaction. For this reason, the investigator is inclined to view the obtained interaction as reflective of the pretest-posttest changes recorded for these particular subjects rather than the general trend that is otherwise suggested.

Although a definite conclusion is not possible on the basis of the evidence available, it might be speculated that verbal behavior analysis supervision may have a more significant effect on teacher-role ideology where the percepts held by student teachers are found to be rather custodial and some modification is desired or necessary. The interaction referred to here is illustrated in Figure 3.

In summary, the investigation seemed to demonstrate the efficacy of approaching the supervision of student teachers in music with an orderly plan for systematic classroom observation including a behavioral focus for employment in the follow-up conference. Without attempting to detract from the merit of the specific behaviors pursued during the course of the study, perhaps the greatest value of verbal behavior analysis supervision derives from the focus it provides for the conference session. The supervisory process, not unlike a number of related educational endeavors, seems to be more effective when conceived on the basis of a clear and unambiguous purpose identified by commonly defined behavioral standards. As the research on teacher behavior continues, it is likely that this process can be sufficiently refined to identify those behaviors more specifically appropriate to the various learning situations encountered, thus reducing further the student teacher's need to rely on inference and intuition.

\section{Implications}

On the basis of the findings reported and conclusions drawn, the following implications are suggested:

1. Verbal behavior analysis has significant potential as a technique of supervision with student teachers of music. The Climate Index is relatively simple to understand and use, provides an effective focus for the supervisor-student teacher conference interaction, and can be employed in a process of nondirective supervision.

2. Student teachers of music appear not to be predisposed to the employment of indirect instructional behaviors as determined by the verbal behavior sampling procedure used in the present study.

3. Student teachers of music can be sensitized to the employment of both learner-centered and teacher-centered verbal patterns in accordance with the purpose and nature of the instruction being provided.

4. The verbal patterns of student teachers in music appear to be 
rather stable and not observably influenced by the grade level of the learners or the nature of the instruction being provided.

5. Verbal behavior analysis supervision tends to encourage objective self-assessment and seems to provide a functional and commonly defined basis for the systematic improvement of teaching performance.

6. Though the evidence supplied by the present study is inconclusive, verbal behavior analysis supervision may hold important implications in cases where extremely custodial teacher-role ideology percepts are held by a student teacher and some modification is desired.

University of Oklahoma

Norman, Oklahoma 